\title{
Baby, it's cold outside. Does it need to be?
}

\author{
Brent Keeling, MD, and Edward P. Chen, MD
}

\author{
From the Division of Cardiothoracic Surgery, Emory University, Atlanta, Ga. \\ Disclosures: Authors have nothing to disclose with regard to commercial support. \\ Received for publication Dec 20, 2016; accepted for publication Dec 27, 2016; available ahead of print Jan 19, \\ 2017. \\ Address for reprints: Edward P. Chen, MD, Division of Cardiothoracic Surgery, Emory University School of Med- \\ icine, 5665 Peachtree Dunwoody Rd, Ste 200, Atlanta, GA 30342 (E-mail: epchen@emory.edu). \\ J Thorac Cardiovasc Surg 2017;153:777-8 \\ $0022-5223 / \$ 36.00$ \\ Copyright (C) 2017 by The American Association for Thoracic Surgery \\ http://dx.doi.org/10.1016/j.jtcvs.2016.12.023
}

Aortic arch surgery has traditionally been performed with deep hypothermic circulatory arrest for cerebral protection, and this neuroprotective strategy continues to be associated with favorable clinical outcomes. Limitations of deep hypothermia include a short safe period of cerebral ischemia and the need for prolonged cardiopulmonary bypass to completely rewarm the patient to normothermia. During the past 15 years, circulation management for aortic arch procedures has increasingly been performed at moderate levels of hypothermia $\left(20^{\circ} \mathrm{C}-28^{\circ} \mathrm{C}\right)$ with varying methods of cerebral perfusion. Unilateral selective antegrade cerebral perfusion or catheter-based bilateral cerebral perfusion have been the most widely used methods of neuroprotection.

Preventza and colleagues ${ }^{1}$ provide an elegant examination with advanced statistical modeling of a large cohort of patients who underwent aortic surgery, all of whom had circulatory arrest times $>30$ minutes. All patients in this study had antegrade cerebral perfusion via either the innominate artery, the right axillary artery, or direct cannulation of the left common carotid artery. More than twothirds of the entire cohort had a bilateral cerebral perfusion strategy employed. The results for the entire cohort are excellent, with low rates of morbidity and mortality in a complex patient population undergoing exceedingly complex aortic procedures.

The true value of this research lies in its examination of the role of deep hypothermia in aortic arch reconstruction. The authors found that there was no short-term survival difference between the deep and moderate hypothermia groups in the adjusted analysis. Subgroup analyses confirmed that even for prolonged antegrade cerebral perfusion times ( $>45$ minutes), there were no short-term survival differences. There were, however, significant differences in the rates of permanent neurologic injury when analyzed according to temperature. When temperature was analyzed as a continuous variable, the stroke rate was significantly higher in patients who underwent deep hypothermia. In

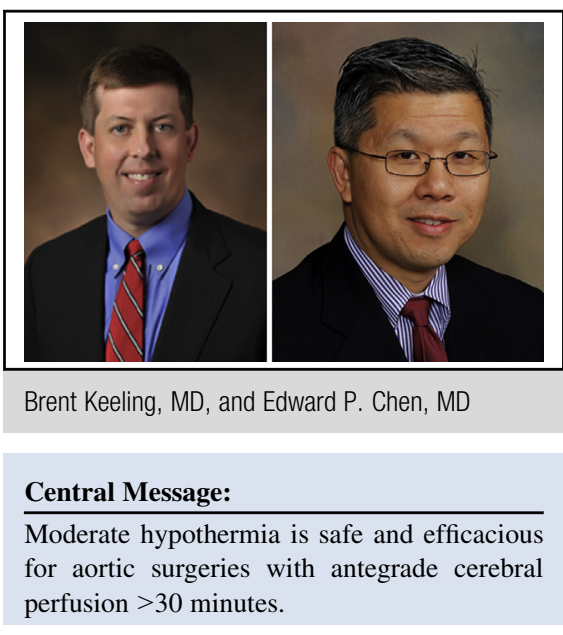

See Article page 767.

patients who had prolonged antegrade cerebral perfusion, similar results were noted. Among the most interesting findings from this research are the long-term survival data. Patients who underwent deep hypothermic circulatory arrest had a significant decrease in their 8-year survival compared with patients who had moderate hypothermic circulatory arrest.

This research is important for its homogeneity of surgical technique. All patients underwent antegrade cerebral perfusion strategies throughout the duration of the study, allowing the authors to draw conclusions based on temperature alone. However, nearly one-quarter of patients experienced an aortic dissection that inevitably resulted in a significant degree of clinical variability. Although the authors attempted to account for this fact through multivariable analysis, the fact remains that patients with entirely different disease processes and varying levels of acuity were included in the study population. While the authors hint at possible bias in the explanation of limitations, there is little explanation as to why some patients underwent deep hypothermia and others did not. One could surmise that the patients who were cooled to lower temperatures had more extensive disease, and this may account for the notable decreases observed in long-term survival for these patients.

Despite the limitations, this research reinforces a vital message that there does not seem to be a benefit of deep hypothermia in the era of antegrade cerebral perfusion for proximal aortic surgery. The question is, Should we 
abandon deep hypothermia altogether due to apparent increases in permanent neurologic deficits? Ultimately, this question may only be answered in the form of a prospective, randomized trial.

\section{Reference}

1. Preventza O, Coselli JS, Akvan S, Kashyap SA, Garcia A, Simpson KH, et al. The impact of temperature in aortic arch surgery patients receiving antegrade cerebral perfusion for $>30$ minutes: how relevant is it really? J Thorac Cardiovasc Surg. 2017; $153: 767-76$. 